\title{
Anti-Homomorphism in Fuzzy Sub Groups
}

\author{
A.Sheik Abdullah \\ Department of Mathematics, Syed hameedha Arts and Science College, \\ Kilakarai-623 806 \\ K.Jeyaraman \\ Department of Mathematics, Alagappa Govt Arts college, \\ Karaikudi-630 003, India
}

\begin{abstract}
In this paper, a new concept of anti-homomorphism between two fuzzy groups $G$ and $G^{\prime}$ is defined many results analogous to homomorphism of groups are established
\end{abstract}

\section{KEYWORDS}

Fuzzy set, fuzzy level subset, fuzzy groups, fuzzy level subgroup, fuzzy normal subgroup, fuzzy abelian subgroup, fuzzy cyclic subgroup homomorphism, Anti-homomorphism, Anti-automorphism.

SUBJECT CLASSIFICATION:- 20 N 25

\section{INTRODUCTION}

After the introduction of fuzzy sets by Zadeh.L.A [10], several researchers explored on the generalization of the notion of fuzzy set. Choudhury.F.P, Chakraborty .A. B and Khare.S.S.[3] defined fuzzy subgroups and fuzzy homomorphisms, Dobritsa.V.P and Yakh Yaeva.G.E discussed homomorphism between two fuzzy groups [4]. Chandrasekhara Rao.K and Gopalakrishnamoorthy.G[1] defined the anti homomorphisms in groups and obtained some results. We define the concept of anti homomorphisms in fuzzy subgroups and normal fuzzy subgroups and establish some results in this Paper.

\section{PRELIMINARIES :}

\subsection{Definition :}

Let $X$ be a non-empty Universal set. A fuzzy subset $\mathrm{A}$ of $\mathrm{X}$ is a function $\mathrm{A}: \mathrm{X} \rightarrow[0,1]$.

\subsection{Definition:}

Let $\mathrm{G}$ be a group. A fuzzy subset $\mathrm{A}$ of $\mathrm{G}$ is said to be a fuzzy subgroup of $\mathrm{G}$ if it is satisfying the following axioms:

(i ) $\mathrm{A}(\mathrm{x} y) \geq \min \{\mathrm{A}(\mathrm{x}), \mathrm{A}(\mathrm{y})\}$, (ii ) $\mathrm{A}\left(\mathrm{x}^{-1}\right) \geq \mathrm{A}(\mathrm{x})$ for all $\mathrm{x}, \mathrm{y} \in \mathrm{G}$

\section{3 Definition :}

Let $\mathrm{A}$ be a fuzzy subset of a set $\mathrm{X}$. For $\mathrm{t} \in[0,1]$, the level subset of $A$ is the set, $A_{t}=\left\{x \in X: \mu_{A}(x) \geq t\right\}$. This is called a fuzzy level subset of A.

\subsection{Definition :}

Let A be a fuzzy subgroup of a group G. The subgroup $A_{t}$ of $G$, for $t \in[0,1]$ such that $t \leq \mu_{A}(e)$ is called a level subgroup of $\mathrm{A}$.

\subsection{Definition :}

A fuzzy subgroup A of a group $\mathrm{G}$ is called fuzzy normal if $\mathrm{A}(\mathrm{x}$ $\mathrm{y})=\mathrm{A}(\mathrm{y} x)$

\subsection{Definition :}

If $(G,$.$) and \left(G^{\prime},.\right)$ are any two groups, then the function $\mathrm{f}: \mathrm{G} \rightarrow \mathrm{G}^{\prime}$ is called a group homomorphism if $\mathrm{f}$ ( $\mathrm{x}$ y ) $=f(x) f(y)$, for all $x$ and $y \in G$.

\subsection{Definition :}

If $(G,$.$) and \left(G^{\prime},.\right)$ are any two groups, then the function $f: G \rightarrow G^{\prime}$ is called a group anti-homomorphism if $f(x y)=f(y) f(x)$, for all $x$ and $y \in G$.

\subsection{Definition :}

Let $X$ and $X^{1}$ be any two sets. Let $f: X \rightarrow X^{1}$ be any function and let A be a fuzzy subset in $\mathrm{X}, \mathrm{V}$ be a fuzzy subset in $\mathrm{f}(\mathrm{X})=\mathrm{X}^{1}$, defined by $\mu_{\mathrm{V}}(\mathrm{y})=\sup \mu_{\mathrm{A}}(\mathrm{x})$, for all

$$
x \in f^{-1}(y)
$$

$\mathrm{x} \in \mathrm{X}$ and $\mathrm{y} \in \mathrm{X}^{1}$. A is called a preimage of $\mathrm{V}$ under $\mathrm{f}$ and is denoted by $\mathrm{f}^{-1}(\mathrm{~V})$.

\subsection{Definition:}

Let $f: G \rightarrow G$ be an anti automorphism if $f(x y)=f(y) f(x)$, for all $x, y \in G$ 


\subsection{Definition:}

Let $\mu$ is a fuzzy characteristic subgroup of a group $\mathrm{G}$ if $\mu(\mathrm{f}(\mathrm{x}))=\mu(\mathrm{x})$

\section{MAIN RESULTS}

\subsection{Theorem :}

Let $\mathrm{f}: \mathrm{G} \rightarrow \mathrm{G}^{\prime}$ be an anti-homomorphism, If $\mu^{\prime}$ is a fuzzy sub group of $\mathrm{G}^{\prime}$.

Then $f^{-1}\left(\mu^{\prime}\right)$ is an fuzzy subgroup of $G$.

\section{Proof.}

Let $\mathrm{x}, \mathrm{y} \in \mathrm{G}$.

Then

$f^{-1}\left(\mu^{\prime}\right)($ x y $)=\mu^{\prime}(f(x$ y $))$

$$
\begin{aligned}
& =\mu^{\prime}(f(y) f(x) \\
& \geq \min \left[\left(\mu^{\prime} f(y)\right),\left(\mu^{\prime}(f(x))\right]\right. \\
& =\min \left[\left(f^{-1} \mu^{\prime}\right)(y),\left(f^{-1} \mu^{\prime}\right)(x)\right]
\end{aligned}
$$

and

$$
\begin{aligned}
\left(f^{-1}\left(\mu^{\prime}\right)\right)\left(x^{-1}\right) & =\mu^{\prime}\left(f\left(x^{-1}\right)\right) \\
& =\mu^{\prime}\left(f^{-1}(x)\right) \\
& =f^{-1}\left(\mu^{\prime}\right)(x)
\end{aligned}
$$

form (1) and (2), the result follows.

Hence $f^{-1}\left(\mu^{\prime}\right)$ is an anti subgroup of $G$.

\subsection{Theorem :}

Let $f: G \rightarrow G^{\prime}$ be an anti-homomorphism. If $\mu$ is a fuzzy group $\mathrm{G}$, Then $\mathrm{f}^{-1}(\mu)$ a fuzzy normal subgroup of $\mathrm{G}^{\prime}$.

\section{Proof.}

For all $\mathrm{x}, \mathrm{y} \in \mathrm{G}$, We have

$$
\begin{array}{r}
\mathrm{f}^{-1}(\mu)(\mathrm{x} y)=\mu(\mathrm{f}(\mathrm{x} \mathrm{y}))=\mu[\mathrm{f}(\mathrm{y}) \mathrm{f}(\mathrm{x})] \\
=\mu(\mathrm{f}(\mathrm{yx})) \\
=\mathrm{f}^{-1}(\mu)(\mathrm{yx})
\end{array}
$$

Which implies that

$$
\mathrm{f}^{-1}(\mu) \text { is a fuzzy normal subgroup of } \mathrm{G}^{1}
$$

\subsection{Theorem :}

Let $f: G \rightarrow G^{\prime}$ be a map, Let $\mu$ be a fuzzy subgroup of $\mathrm{G}$. Let $\mathrm{f}$ be a surjective anti homomorphism, Then $f(\mu)$ is a normal subgroup of $\mathrm{G}^{\prime}$

Proof.

Each level subgroup of $\mu$ is a subgroup in G.

But $\mathrm{f}$ is a surjective anti homomorphism.

Hence $(\mathrm{f}(\mu))_{\mathrm{t}}, \mathrm{t} \in \operatorname{Im}(\mu)$, is anti homomorphic image of some level subgroup of $\mu$.
It follows that $(f(\mu))_{t}$ is a normal subgroup of $G$.

A second application of theorem2.3.2 of Rajesh kumar "Fuzzy Algebra" gives that

$\mathrm{f}(\mu)$ is a fuzzy normal subgroup of $\mathrm{G}^{\prime}$.

\subsection{Theorem :}

A fuzzy characteristic sub group of a fuzzy group is a normal fuzzy sub group.

Proof.

Let $\mathrm{f}$ be an anti automorphism of $\mathrm{G}$

Which implies

$$
f(y x)=f(y)(x) \text { for all } x, y \in G
$$

Which implies

$\mu(\mathrm{x} \mathrm{y})=\mu(\mathrm{f}(\mathrm{y} \mathrm{x}))$ because $\mu$ is a characteristic fuzzy sub group $\mathrm{G}$

Which implies

$\mu(\mathrm{x} \mathrm{y})=\mu(\mathrm{f}(\mathrm{y}) \mathrm{f}(\mathrm{x}))$ because $\mathrm{f}$ is a anti automorphism of $\mathrm{G}$

$$
\begin{aligned}
& =\mu(\mathrm{f}(\mathrm{yx}) \\
& =\mu(\mathrm{y} x) \text { since } \mu \text { is a }
\end{aligned}
$$

characteristic fuzzy sub group $\mathrm{G}$

Hence $\mu$ is a normal fuzzy sub group of $G$

\subsection{Definition :}

Let $\mu$ be a fuzzy subgroup of a group $\mathrm{G}$.

Let $H=\{x \in G / \mu(x)=\mu(e)\}$. Then $\mu$ is a fuzzy abelian subgroup of $\mathrm{G}$.

\subsection{Theorem:}

Anti-homomorphism pre image of a fuzzy abelian subgroup is a fuzzy abelian subgroup.

\section{Proof:}

let $\mu$ is a fuzzy subgroup of $\mathrm{G}$

To prove $\mu$ is a fuzzy abelian subgroup of $\mathrm{G}$

Let $\gamma$ be a fuzzy abelian subgroup of $\mathrm{G}^{\prime}$

Since $\mu$ be a fuzzy subgroup of $\mathrm{G}$ and $\gamma$ is a fuzzy abelian subgroup of $\mathrm{G}^{\prime}$

Then $\mathrm{U}=\left\{\mathrm{y} \in \mathrm{G}^{\prime} / \gamma(\mathrm{y})=\gamma\left(\mathrm{e}^{\prime}\right)\right\}$ is an fuzzy abelian group of $\mathrm{G}^{\prime}$,

where $\mathrm{e}^{\prime}$ is the identity of $\mathrm{G}^{\prime}$.

Consider the set

$\mathrm{H}=\{\mathrm{x} \in \mathrm{G} / \mu(\mathrm{x})=\mu(\mathrm{e})\}$ where $\mathrm{e}$ is the identity of $\mathrm{G}$

Let $\mathrm{x} y \in \mathrm{H} \subseteq \mathrm{G}$.

Then $\mu\left(\begin{array}{ll}x & y\end{array}=\mu(e)\right.$

$$
\gamma(\mathrm{f}(\mathrm{x} \mathrm{y}))=\gamma(\mathrm{f}(\mathrm{e}))
$$




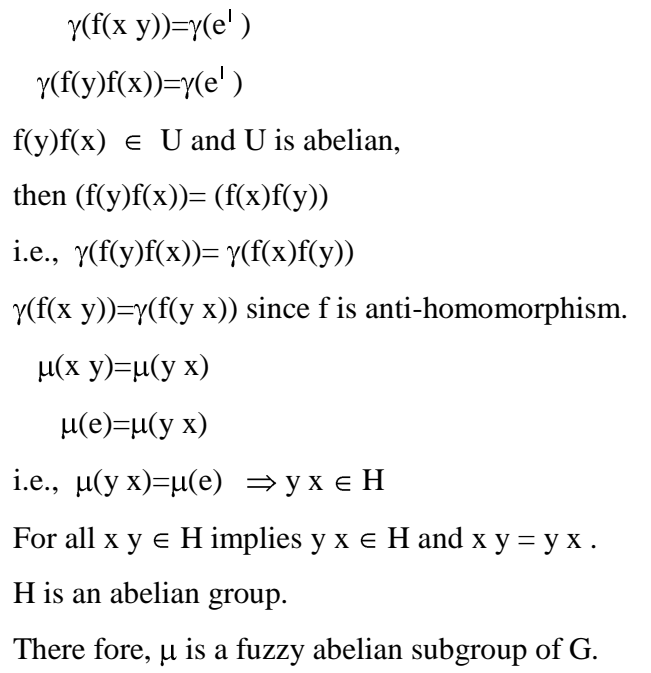

\subsection{Theorem :}

Anti homomorphism image of a fuzzy abelian subgroup is a fuzzy abelian subgroup.

\section{Proof:}

Let $\gamma$ is a fuzzy subgroup of $\mathrm{G}^{\prime}$

To prove $\gamma$ is a fuzzy abelian subgroup of $\mathrm{G}^{\prime}$.

Let $\mathrm{f}$ be an anti homomorphism from $\mathrm{G}$ to $\mathrm{G}^{\prime}$.

Since $\mu$ be an fuzzy abelian subgroup of $\mathrm{G}$

Then $\mathrm{H}=\{\mathrm{x} \in \mathrm{G} / \mu(\mathrm{x})=\mu(\mathrm{e})\}$ is an abelian subgroup of $\mathrm{G}^{\prime}$

where $\mathrm{e}$ is the identity element of $\mathrm{G}$.

Let $\gamma$ be the fuzzy subgroup of $\mathrm{G}^{\prime}$.

Let $\mathrm{U}=\left\{\mathrm{y} \in \mathrm{G}^{\prime} / \gamma(\mathrm{y})=\gamma\left(\mathrm{e}^{\prime}\right)\right\}$ where $\mathrm{e}^{\prime}$ is the identity element $G^{\prime}$.

$$
\begin{aligned}
& \text { Let } \mathrm{x} \mathrm{y} \in \mathrm{U} \subseteq \mathrm{G}^{\prime} \\
& \begin{aligned}
& \gamma(\mathrm{x} y)=\gamma\left(\mathrm{e}^{\prime}\right) \\
& \operatorname{Sup} \quad \mu(\mathrm{t})= \sup \mu(\mathrm{t}) \\
& \mathrm{t} \in \mathrm{f}^{-1}(\mathrm{x} \mathrm{y}) \quad \mathrm{t} \in \mathrm{f}^{-1}\left(\mathrm{e}^{\prime}\right)
\end{aligned} \\
& \mu(\mathrm{x} \mathrm{y})=\mu(\mathrm{e})
\end{aligned}
$$

Then $\mathrm{x} y \in \mathrm{H}$ and $\mathrm{H}$ is abelian

$$
\begin{gathered}
\mathrm{xy}=\mathrm{yx} \\
\mu(\mathrm{x} \mathrm{y})=\mu(\mathrm{yx})
\end{gathered}
$$

$$
\begin{aligned}
& \text { Sup } \mu(\mathrm{t})=\sup \mu(\mathrm{t}) \\
& \mathrm{t} \in \mathrm{f}^{-1}(\mathrm{x} y) \quad \mathrm{t} \in \mathrm{f}^{-1}(\mathrm{yx}) \\
& \gamma(\mathrm{x} \mathrm{y})=\gamma(\mathrm{y} \mathrm{x}) \\
& \gamma\left(\mathrm{e}^{\mathrm{c}}\right)=\gamma(\mathrm{y} \mathrm{x}) \\
& \text { ie, } \quad \gamma(\mathrm{xy})=\gamma\left(\mathrm{e}^{\mathrm{l}}\right) \Rightarrow \mathrm{yx} \in \mathrm{U}
\end{aligned}
$$

For all $\mathrm{x} y \in \mathrm{U}$ implies $\mathrm{y} x \in \mathrm{U}$ and $\mathrm{x} \mathrm{y}=\mathrm{y} \mathrm{x}$.

Then $U$ is abelian subgroup of $\mathrm{G}^{\prime}$

Therefore $\gamma$ is a fuzzy abelian subgroup of $\mathrm{G}^{1}$.

\subsection{Definition:}

Let $\mu$ be a fuzzy subgroup of $\mathrm{G}$ then $\mu$ is called a cyclic fuzzy subgroup if $\mu_{\mathrm{t}}$ is a cyclic subgroup for all $\mathrm{t} \in[0,1]$, where $\mu_{\mathrm{t}}=\{\mathrm{x} \in \mathrm{G} / \mu(\mathrm{x}) \geq \mathrm{t}\}$.

\subsection{Theorem:}

Anti homomorphism pre-image of cyclic fuzzy subgroup is a cyclic fuzzy subgroup

\section{Proof:}

Let $\mu$ is a fuzzy subgroup of $\mathrm{G}$

To prove $\mu$ is a cyclic fuzzy subgroup of $\mathrm{G}$

Let $f$ be an anti homomorphism from $G$ into $G^{\prime}$

Let $\gamma$ be a cyclic fuzzy subgroup of $\mathrm{G}^{\prime}$ and Since $\mu$ be a fuzzy subgroup of $\mathrm{G}$.

Now, for any $t \in[0,1]$,

$\mu_{\mathrm{t}}=\{\mathrm{x} \in \mathrm{G} / \mu(\mathrm{x}) \geq \mathrm{t}\}$.Since $\gamma$ be a cyclic fuzzy subgroup of $\mathrm{G}^{\prime}$,

then $\mu_{\lambda}$ is a cyclic subgroup of $\mathrm{G}^{\prime}$.

Clearly $\mathrm{f}^{-1}\left(\mu_{\lambda}\right) \subseteq \mu_{\mathrm{t}}$

Then $\mu_{\mathrm{t}}$ is cyclic and hence $\mu$ is a cyclic fuzzy subgroup of G .

\subsection{Theorem:}

Anti homomorphism image of cyclic fuzzy subgroup is a cyclic fuzzy subgroup

\section{Proof :}

Let $\gamma$ is a fuzzy subgroup of $\mathrm{G}^{\prime}$

To prove $\gamma$ is a cyclic fuzzy subgroup of $\mathrm{G}$

Let $f$ be an anti homomorphism from $G$ into $G^{\prime}$

Let $\mu$ be a cyclic fuzzy subgroup of $\mathrm{G}$ and $\gamma$ be a fuzzy subgroup of $\mathrm{G}^{\mathrm{l}}$

Clearly $\mu_{\mathrm{t}}$ is a cyclic subgroup of $\mathrm{G}$ for $\mathrm{t} \in[0,1]$,

and $\mathrm{f}\left(\mu_{\mathrm{t}}\right) \subseteq \mu_{\lambda}$ for $\lambda \in[0,1]$,

Then $\gamma_{\lambda}$ is a cyclic

Hence $\gamma$ is a cyclic fuzzy subgroup of $\mathrm{G}^{\prime}$.

\section{REFERENCES}

[1] Chandrasekhara Rao .K and Gopalakrishnamoorthy.G, antihomomorphisms in groups, Jr of Inst.of Maths and Comp Sciences (Math.ser) 9, (2006),45-55

[2] Chandrasekhara Rao .K and Swaminathan.V, antihomomorphism in Near rings. Jr of Inst.of maths and computer sciences(Math.ser) 2,(2006),83-88 
[3] Choudhury.F.P, Chakraborty.A.B. and Khare.S.S. , A note on fuzzy subgroups and fuzzy homomorphism .Journal of Mathematical analysis and Applications 131 , (1988 ),537 -553 .

[4] Dobritsa.V.P and Yakh yaeva.G.E, on homomorphism of fuzzy grouop,Siberian Mathematicl Joural .43(2002),47-51

[5] Jeyaraman.K and Sheik Abdullah.A, The homomophism and anti-homomorphism of Level subgroups of fuzzy sub groups, International Journal of Mathematical Forum 5,(2010),2293-2298.

[6] Mohamed Asaad , Groups and fuzzy subgroups , Fuzzy sets and Systems (1991), North-Holland .
[7] Palaniappan. N and Arjunan. K, The homomorphism, anti homomorphism of a fuzzy and an anti fuzzy ideals, Varahmihir Journal of Mathematical Sciences, 6 , (2006), 181-188.

[8] Rajesh kumar, Fuzzy Algebra, Delhi University Publication.

[9] Sheik Abdullah.A and Jeyaraman.K, Anti-homomorphisms in fuzzy ideals of rings, Int.J.Contemp.Math.Sciences,5 , (2010),2717-2721

[10] Zadeh.L.A, Fuzzy sets, Information and Control, 8, (1965), 338-353. 